\title{
Integrating Physical Expert Systems to Forecast Taiwan Stock Behavior
}

\author{
Chiu-Chin Chen and Chia-Chun Liao
}

\begin{abstract}
This technical analysis includes two parts, the technical indicators and the trends. Many researches have applied technical indicators in the financial decision area, but few researches have applied the wave principle to the trends. The extract $\mathrm{N}$-wave under Elliott Wave characteristics using the back-propagation neural network (BPNN) method is applied in this work. The results showed that integrating RSI and MACD with the $\mathrm{N}$-wave provides better accuracy and profitability prediction than considering only the $\mathrm{N}$-wave physical quantity. RSI represents the short-term disturbance and MACD represents the long-term trends. The results show that long-term and short-term physical quantities also have control ability on the stock market. This study establishes an intelligent model that provides original value retrospect indicators that present more confident recommendations to investors.
\end{abstract}

Index Terms-Technical analysis, the Elliott wave principle, $\mathrm{N}$-wave technical indicator, back-propagation neural network (BPNN).

\section{INTRODUCTION}

The financial markets have been increasingly turbulent over the past five years. The Chicago Board of Trade was founded in 1848. The Preparatory Office of the Taiwan Futures Exchange was established in December, 1996 [1]. Over the past twenty years the Exchange launched various types of derivative financial instruments, while the government reduced taxes and promoted electronic trading. While facing property redistribution and derivatives, the financial industry continues to introduce new investment aids. A set of optimal investment strategies were proposed that can take risks and obtain the best opportunity to buy and sell, set up a stop-loss point and stopping point for interest, in the hope to reduce risk and maximize returns.

Technical analysis is widely used in the financial investment field [2]. The technical analysis indicators are divided into classes and type categories [3]. The technical indicators used in financial decision-making in the historical research investment field have a long history. Other types of fluctuations can represent the class principle from Eliot. Eliot summed the wheeled stock market and proposed the wave theory in 1930 to explain stock market trends. Related research is currently used in the field to explore Wave

Manuscript received August 2, 2016; revised December 1, 2016. This research is supported by the "Ministry of Science and Technology" of Taiwan under the grant No. 105-2410-H-346 -001.

Chiu-Chin Chen is with the Department of Information Management, National Penghu University of Science and Technology, 300 Liuhe Rd., Magong, Penghu 880, Taiwan, R.O.C. (e-mail: jennifer@gms.npu.edu.tw).

Chia-Chun Liao was with the Department of Business Administration, National Central University, 300 Zhongda Rd., Zhongli District, Taoyuan City 32001, Taiwan, R.O.C. (e-mail: jonathan.liao.mis@gmail.com).
Principle financial investment decisions [4], proposed to capture the N-type waves through the features used in the futures market. Wave mechanics really explain the nature of the stock market moving wheel. From the technical analysis theory point of view there is no technical indicator integration in the current wave patterns related science research [5]. This study uses Wave theory technical indicators to formulate a comprehensive evaluation of the physical forces to explore the rule of conduct in financial markets.

\section{METHODOLOGY}

Charles H. Dow originated stock market technical analysis in 1884. The Dow index data was used to launch the Dow Jones Industrial Average (DJIA) and the Dow Jones Transportation Index (DJTA) within five years. There after Hamilton (William Peter Hamilton) and Rhea (Robert Rhea) provided a complete discussion of the Dow Theory [6]. Dow used ocean tide observation, analysis and interpretation for the stock market to forecast the future direction of the stock price [7], [8].

An overview of the aforementioned literature shows the autocorrelation relative strength index has utility in nature, with similarities and differences between the exponential smoothing moving average, momentum indicators and trend indicators. There has been little research on the number of integrations, but the financial markets have found effective use of the Elliott Wave Principle application in artificial intelligence back-propagation neural network model to construct learning. The non-random behavior of the Taiwan weighted Stock Index and performance of the physical forces can be used to grasp the non-random behavior rules. This work will explore the different physical quantities used in $\mathrm{N}$-wave theory, as a trading strategy using the $\mathrm{N}$-wave technical indicator to achieve better stock trading performance.

\section{MODEL IMPLEMENTATION}

These experiments are divided into two phases. The first phase is conducted in five experiments. These five experiments constitute one group; working together to use the data collected from 60 days of N-type wave technical indicators. Experiment one will use different technical indicators to explore the sum of behavior of different physical forces. The first four experiments use the RSI, Exponential moving Average Convergence Divergence line, momentum indicators and trend indicators. The relatively high profitability and accuracy of the predictive capability of these technical indicators can be obtained from the preliminary 
experimental results. The RSI and MACD technical indicator combinations consider 60 days physical strength of N-type wave technical indicators processed through a back propagation network as the input variables. Experiments one to five are analyzed and compared to the experimental architecture diagram in Fig. 1 as the first stage of the five experimental groups.

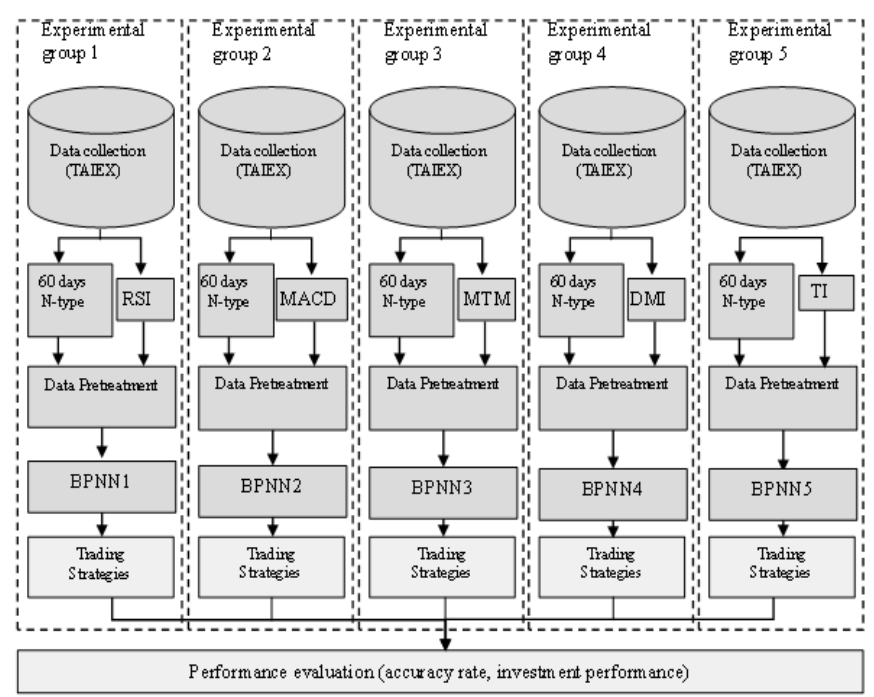

Fig. 1. The first stage experiment chart.

After the first phase of the experiment the results are filtered for experimental group performance. Experimental group II, the second phase, is analyzed for predictive ability and profitability to compare the control group predictive power. From February 7, 1987 to February 6, 2009, a total of 23 years of TAIEX data were compiled. Integrity and due consideration when another quarter, only 60 days after N-type information, according to the conditions found after further experiments to obtain the input data for the 7:3 split, enabling back-propagation neural network to learn and test to achieve the best results. From February 7, 1987 to August 7, 2002 a total of 15 and a half years of data were used as the training data for August 7, 2002 to February 6, 2009 a total of 7 years, half of the data used as test data.

\section{EXPERIMENTAL RESULTS}

This section analyzes the first phase experiment empirical results. Experiments one to five were analyzed and compared, and screened for better investment performance relative performance. The second phase of the experimental analysis was then conducted. The experimental and control groups from the neural network model parameter setting, the length of some similarities and differences during the formation of N-type were compared. When the second phase of the experiment was screened against the first phase a second random experiment transaction was conducted. The second phase is divided into two smaller parts. The first is the experimental group and control group doing a random transaction. The second part is two experimental groups, the control group and the control group, with two transactions done randomly. The profit forecast, the ability to predict, and overall performance evaluation were conducted.

\section{A. The First Stage Experiment}

The first stage uses different numbers of technical indicators, integrated $\mathrm{N}$-type wave trading strategy simulated 300 times, a comprehensive performance comparison, five comprehensive experiments used to compare the experimental group as shown in Table I. The physical and $\mathrm{N}$ -type waves in the first experiment group are integrated. The total accuracy rate of five experiments was $95.74 \%, 93.92 \%$, $83.80 \%, 84.47 \%$ and $83.97 \%$. Experimental group one was second in total accuracy. The experimental group accuracy rose from one to five as $95.50 \%, 88.74 \%, 75.62 \%, 78.80 \%$ and $85.81 \%$. The experimental results increased a second accuracy with a total accuracy rate much higher than three. The conclusion in the experimental group of five of the four experimental groups fell to the accuracy of experimental group one. Four groups were higher than $90 \%$.

TABLE I: EXPERIMENTAL GROUP OF ONE TO FIVE EXPERIMENTAL GROUPS SIMULATED TRADING RESULTS OF THE COMPARISON TABLE 30 VIEWS

\begin{tabular}{|c|c|c|c|c|c|}
\hline Item & $\begin{array}{l}\text { Experimental } \\
\text { group } 1(\mathrm{RSI})\end{array}$ & $\begin{array}{l}\text { Experimental } \\
\text { group } 2 \\
(\text { MACD })\end{array}$ & $\begin{array}{l}\text { Experimental } \\
\text { group } 3 \text { (MTM) }\end{array}$ & $\begin{array}{l}\text { Experimental } \\
\text { group } 4(\mathrm{DMI})\end{array}$ & $\begin{array}{l}\text { Experimental } \\
\text { group 5( RSI 、 } \\
\text { MACD ) }\end{array}$ \\
\hline Accuracy rate surged & $95.50 \%$ & $88.74 \%$ & $75.62 \%$ & $78.80 \%$ & $85.81 \%$ \\
\hline Crumbled accuracy rate & $95.97 \%$ & $99.10 \%$ & $91.97 \%$ & $90.14 \%$ & $82.13 \%$ \\
\hline Overall accuracy rate & $95.74 \%$ & $93.92 \%$ & $83.80 \%$ & $84.47 \%$ & $83.97 \%$ \\
\hline The single biggest profit & 619.26 & 587.37 & 512.22 & 625.76 & 625.76 \\
\hline The single biggest loss & -160.43 & -161.28 & -275.02 & 251.54 & 177.68 \\
\hline $\begin{array}{l}\text { Average earnings soared } \\
\text { Points }\end{array}$ & 414.62 & 323.28 & 198.4 & 208.5 & 298.2 \\
\hline $\begin{array}{l}\text { Average earnings Crash } \\
\text { Points }\end{array}$ & 356 & 436.3 & 135.64 & 255.87 & 266.21 \\
\hline Average profit pips & 385.29 & 379.79 & 166.99 & 232.19 & 282.23 \\
\hline
\end{tabular}

\section{B. The Second Stage Experiment}

Table II Experiment. Consider the first phase of the second stage of screening performance better performance of the two experimental groups will be evaluated in two parts for comparison. Accuracy of part two of the experimental groups 
showed the control group results for two random trading transactions increased. The accuracy rates were $88.74 \%$, $85.72 \%$ and $54.69 \%$, respectively. The falling accuracy rates were $99.10 \%, 72.21 \%, 61.63 \%$. The total accuracy rates were $93.92 \%, 80.89 \%$ and $58.16 \%$, respectively. The above data shows that the experimental group results were higher than that for control group II. If the similarities and differences between the exponential smoothing moving average integrated $\mathrm{N}$-type theory within 60 days, obtain better results using only the N-type wave trading strategies; and If the random trading strategy does not take into account any physical force, the result will be significantly worse than the experimental results considering the physical forces.

TABLE II: Two EXPERIMENTAL Groups, THE CONTROL GRoup AND THE CONTROL Group, Two OF 30 TrANSACTIONS DONE RANDOMLy SiMUlATED TRADING RESULTS COMPARISON TABLE

\begin{tabular}{lccc}
\hline \hline \multicolumn{1}{c}{ Item } & $\begin{array}{c}\text { Experimental } \\
\text { group 2 } \\
\text { (MACD) }\end{array}$ & $\begin{array}{c}\text { Control } \\
\text { group }\end{array}$ & $\begin{array}{c}\text { Control group 2 } \\
\text { Random } \\
\text { transaction } \\
\text { (MACD) }\end{array}$ \\
\hline Accuracy rate surged & $88.74 \%$ & $85.72 \%$ & $54.69 \%$ \\
$\begin{array}{l}\text { Crumbled accuracy } \\
\text { rate }\end{array}$ & $99.10 \%$ & $76.21 \%$ & $61.63 \%$ \\
$\begin{array}{l}\text { Overall accuracy rate } \\
\text { Average earnings }\end{array}$ & $93.92 \%$ & $80.89 \%$ & $58.16 \%$ \\
$\begin{array}{l}\text { soared Points } \\
\text { Average earnings } \\
\text { Crash Points } \\
\text { Average profit pips }\end{array}$ & 323.28 & 337.60 & 35.86 \\
\hline \hline
\end{tabular}

TABLE III: EXPONENTIAL MOVIng AVERAGE CONVERGENCE DIVERGENCE LINE COST ANALYSIS

\begin{tabular}{|c|c|c|c|c|c|}
\hline \multicolumn{6}{|c|}{ long strategy } \\
\hline $\begin{array}{c}\text { DIF } \\
\text { Value }\end{array}$ & $\begin{array}{l}\text { Average } \\
\text { profit pips }\end{array}$ & $\begin{array}{c}\text { The deal of } \\
\text { investment } \\
\text { rates }\end{array}$ & $\begin{array}{c}\text { MACD } \\
\text { Value }\end{array}$ & $\begin{array}{l}\text { Average profit } \\
\text { pips }\end{array}$ & $\begin{array}{c}\text { The deal of } \\
\text { investment } \\
\text { rates } \\
\end{array}$ \\
\hline$>200$ & 77.34 & $2.70 \%$ & $>200$ & 77.34 & $2.78 \%$ \\
\hline $\begin{array}{c}100 \sim \\
200\end{array}$ & 253.69 & $13.51 \%$ & $100 \sim 200$ & 197.30 & $11.11 \%$ \\
\hline $0 \sim 100$ & 136.54 & $37.84 \%$ & $0 \sim 100$ & 121.56 & $47.22 \%$ \\
\hline$-100 \sim 0$ & 115.54 & $24.32 \%$ & $-100 \sim 0$ & 195.98 & $16.67 \%$ \\
\hline $\begin{array}{c}-200 \sim \\
-100\end{array}$ & 161.52 & $13.51 \%$ & $-200 \sim-100$ & 312.54 & $8.33 \%$ \\
\hline $\begin{array}{c}-300 \sim \\
-200\end{array}$ & 353.61 & $2.70 \%$ & $-300 \sim-200$ & 216.58 & $5.56 \%$ \\
\hline$<-300$ & 18.535 & $5.41 \%$ & $<-300$ & 130.23 & $8.33 \%$ \\
\hline \multicolumn{6}{|c|}{ short strategy } \\
\hline $\begin{array}{c}\text { DIF } \\
\text { Value }\end{array}$ & $\begin{array}{l}\text { Average } \\
\text { profit pips }\end{array}$ & $\begin{array}{c}\text { The deal of } \\
\text { investment } \\
\text { rates }\end{array}$ & $\begin{array}{l}\text { MACD } \\
\text { Value }\end{array}$ & $\begin{array}{l}\text { Average profit } \\
\text { pips }\end{array}$ & $\begin{array}{c}\text { The deal of } \\
\text { investment } \\
\text { rates }\end{array}$ \\
\hline$>200$ & -77.34 & $4.34 \%$ & $>200$ & NA & NA \\
\hline $\begin{array}{c}100 \sim \\
200\end{array}$ & 486.76 & $4.34 \%$ & $100 \sim 200$ & 218.79 & $12.5 \%$ \\
\hline $0 \sim 100$ & 265.20 & $21.73 \%$ & $0 \sim 100$ & 206.05 & $25 \%$ \\
\hline$-100 \sim 0$ & 278.334 & $26.09 \%$ & $-100 \sim 0$ & 127.08 & $29.17 \%$ \\
\hline $\begin{array}{c}-200 \sim \\
-100\end{array}$ & 343.14 & $17.39 \%$ & $-200 \sim-100$ & 306.36 & $16.67 \%$ \\
\hline $\begin{array}{c}-300 \sim \\
-200\end{array}$ & 169.26 & $17.39 \%$ & $-200 \sim-300$ & 446.12 & $4.17 \%$ \\
\hline$<-300$ & 625.76 & $4.34 \%$ & $<-300$ & 136.08 & $8.33 \%$ \\
\hline
\end{tabular}

\section{Moving Average Convergence Divergence Analysis}

When the number and average profit investment rates are present, the available space as trading strategies, in DIF between 0-100 and the MACD is between 0-100, the highest return on investment can be obtained. Long-term Trading Strategies are appropriate when the DIF is between -100 and 0 , and the MACD is between -200 to -100 , the relatively highest investment returns are possible. This empirical research used the original value of the empty trading strategy with less 
obvious analysis results showing that the N-type wave is long-term. If the DIF MACD fast line and the slow lane are between $0-100$, relatively higher investment profits are possible. Table III below selects the higher than average profit rate and higher data analyzed between DIF and MACD providing investment confidence among investors of any better value.

\section{CONCLUSIONS}

This study attempts to integrate the technical indicators technical classes while considering the band and trends of $\mathrm{N}$ -type waves. The similarities when compared with the simple use of the N-type waves technical indicators using the back-propagation neural network simulation for thirty trading strategies. The experimental results were obtained as follows: Using RSI and MACD indicators integrated into the $\mathrm{N}$-type two- wave theory when after the $90 \%$ confidence interval for statistical testing, technical indicators integrated $\mathrm{N}$-type wave alone can indeed produce a superior trading strategy. $\mathrm{N}$-type wave accuracy of predictive capability while also significantly better than the prediction ability and accuracy profitability of the random trading strategy. In the stock market forming a wavy curve between points can be divided into factors affecting the band's long-term trends and shortwavelength perturbations. RSI analysis confirmed the integration of $\mathrm{N}$-type waves can have excellent investment performance. This means that short-term technical indicators RSI and $\mathrm{N}$-type wave energy integration can highlight the short-term stock price line. Another MACD integrated N -type wave energy approach can highlight the long-term trend line. The sum of the analysis results is as follows: Using RSI and MACD integrated with $\mathrm{N}$-type waves predicts the energy highlight short, medium and long term stock market wheeled physical forces and strengthens the physical benefits of convergence when investing significant amounts and thus control for the non-random behavior of the stock market .

\section{REFERENCES}

[1] Y. Zhao, Y. Zhang, and C. J. Qi, "Futures margin forecasting and simulating based on multiscale-IGARCH model," Journal of Computational Information Systems, vol. 6, no. 6, pp. 1843-1853, 2010.
[2] Intermarket Technical Analysis: Trading Strategies for the Global Stock, Bond, Commodity and Currency Markets, Murphy JJ, 1991.

[3] L. D. Blume and M O'Hara, "Market statistics and technical analysis: The role of volume," The Journal of Finance, vol. 49, no. 1, pp. 153, 1994.

[4] Elliott Wave Principle, Gainesville, GA: New Classics Library, Frost $\mathrm{AJ}$ and Prechter RJ, 2005.

[5] K. T. Kimoto and Asakawa, "Stock market prediction system with modular neural networks," in Proc. 1990 IJCNN International Joint Conference on Neural Networks, vol. 1, pp. 11-16, 1990.

[6] The Dow Theory: An Explanation of Its Development and an Attempt to Define Its Usefulness as an Aid in Speculation, Fraser Publishing Company, R. Robert and H. Charles, 1993.

[7] C. P. Neely and R. W. Dittmar, "Is technical analysis in the foreign exchange market profitable? A genetic programming approach," The Journal of Financial and Quantitative Analysis, vol. 32, no. 4, pp. 405, 1997.

[8] B. E. ZhangPatuwo and M. Y. G. Hu, "Forecasting with artificial neural networks: the state of the art," International Journal of Forecasting, vol. 14, no. 1, pp. 35-62, 1998.

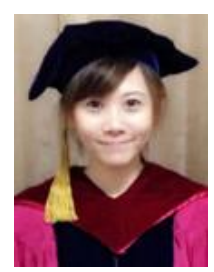

Chiu-Chin Chen is an Assistant Professor of the Department of Information Management, National Penghu University of Science and Technology. She holds a Ph.D. in the information management from National Chiao Tung University. Her major interests are in the area of Financial Investment Decision, Artificial Intelligence and System Simulation and Optimization Theory and Applications.

She has published over 20 journal and conference papers. Her recent research interests are in Cloud Computing, Collaborative Technology, Financial Management, and E-Learning System.

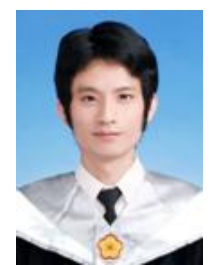

Chia-Chun Liao is an Assistant Professor. He holds a Ph.D. in the management from National Central University. His major interests are in the area of Technology Management, Service Science, Software Quality Engineering, System Evaluation, Grey System, Optimization Theory and Applications.

He has published over 20 journal and conference papers. His recent research interests are in Cloud Computing, Technology Management, and Service Science. 

Computer Networks and Applications 
